\title{
LA ILUSTRACIÓN DE MADRID (1870-1871). REVISTA DE TRANSICIÓN DEL ROMANTICISMO AL REALISMO
}

\author{
JESÚS RUBIO JIMÉNEZ \\ Universidad de Zaragoza
}

\section{Resumen}

La Ilustración de Madrid (1870-1871) fue una revista que trató de aunar información política y cultural con una presentación gráfica cuidada, realizada por artistas españoles.

Dirigida por Gustavo Adolfo Bécquer e impulsada en su parte gráfica por Valeriano Bécquer, la revista perdió en gran parte su orientación cuando fallecieron los dos hermanos, Valeriano en septiembre y Gustavo Adolfo en diciembre de 1870. Aun así sobrevivió una año más y resulta hoy una de las publicaciones periódicas fundamentales para el estudio de la transición del romanticismo al realismo.

Palabras clave: Gustavo Adolfo Bécquer, Valeriano Bécquer, Romanticismo, Realismo, Prensa literaria, Ilustración gráfica.

\begin{abstract}
La Ilustración de Madrid (1870-1871) (Enlightenment in Madrid) was a magazine that tried to unite political and cultural information with a delicate graphics presentation from spanish artists.

It was directed by Gustavo Adolfo Bécquer and promoted by Valeriano Bécquer in its graphic side. The magazine lost a big part of situation when the two brothers, Valerieano in September and Gustavo Adolfo in December of 1870, passed away. Even so it survived a year longer and it is considered one of the most fundamental journalistic publications of the study of the transition from romanticism to realism.
\end{abstract}

Keywords: Gustavo Adolfo Bécquer, Valeriano Bécquer, Romanticism, Realism, Literary press, Graphic illustrations.

Anales, 26, 2014, pp. 451-471

DOI: 10.14198/ALEUA.2014.26.19 
La Ilustración de Madrid ha sido recordada especialmente porque fue promovida y dirigida por Gustavo Adolfo Bécquer desde su inicio el 12 de enero de 1870 hasta la muerte del poeta el 22 de diciembre de 1870 (Sáinz Medrano, 1970. Pageard, 1990. Álvarez Rubio, s. d. Rubio Jiménez, 2009). Hasta se han reeditado en edición facsimilar las páginas atribuidas al poeta y las imágenes surgidas de los dibujos de su hermano Valeriano para ilustrarlas, aunque sin precisión en las identificaciones (Cabra Loredo ed., 1983).

La temprana desaparición de Gustavo Adolfo, director literario y alma del proyecto, cuando se cumplía el primer año de andadura de la revista, dio lugar a escritos de despedida y a la inclusión de algunos poemas suyos. Valeriano, que había sido pieza fundamental en la orientación gráfica de la revista y que había fallecido apenas unos meses antes que su hermano, también fue homenajeado en sus páginas. Y la revista adquirió ahora un último lote de dibujos de sus carteras, que se fueron publicando grabados en 1871. Con el dinero obtenido se ayudó a sufragar los gastos de la primera edición de las Obras (Madrid, Fortanet, 1871, 2 tomos) del poeta, que se realizó gracias a una suscripción pública promovida por sus amigos. Las circunstancias de la compra de estos dibujos y todo el proceso de edición de las Obras lo describí en 2009, recuperando el folleto de la Suscripción Bécquer donde la comisión gestora rindió cuentas de la tarea llevada a cabo (Rubio Jiménez, 2009).

La muerte de Valeriano en septiembre de 1870 dio lugar a la inclusión en el número 19, correspondiente al 12 de octubre, de una emotiva necrología de Ramón Rodríguez Correa - «Don Valeriano Domínguez Bécquer»-, su retrato dibujado por Alfredo Perea y grabado por Paris -«Don Valeriano Bécquer»- y otro grabado sobre un dibujo de Martín Rico - «Recuerdo a Bécquer, de Martín Rico»-, que evocaba al artista con una composición que mezclaba paisaje y una cruz de piedra antigua, recordando su pintura viajera y en cierto modo la Cruz negra del Monasterio de Veruela. Rodríguez Correa, que contó para realizar su semblanza con unas cuartillas escritas por Gustavo Adolfo sobre su hermano (Balbín Lucas, 1954), se refirió a cómo «desde niños la desgracia fue la nodriza de ambos hermanos», al haber quedado huérfanos, pero «también fueron sus fieles compañeros la resignación, el arte y el genio.» ${ }^{1}$ Tras repasar su trayectoria, destacando que «dibujar y pintar eran en él una pasión», aludió a cómo se encontraba en esos momentos Gustavo Adolfo: «El poeta vive,

1. Los textos de la revista se citan en adelante actualizando su ortografía y signos de puntuación. Remito a los 48 números de la revista indicando el número correspondiente entre paréntesis en el cuerpo del texto. No se analizan aquí los Almanaques que publicaron para 1871 y 1872, que en gran parte recopilan materiales publicados en la revista a lo largo de los respectivos años anteriores. 
y llora a su perdido hermano. Tenemos la confianza de que su nombre, si logra algún día verse desligado de las misteriosas necesidades del momento, figurará con gloria en nuestro Parnaso.»

Lo que no podía imaginar Rodríguez Correa es que, apenas unos meses después, también Gustavo Adolfo fallecería prematuramente. Fue ahora Narciso Campillo el encargado de escribir la necrología del poeta conmovido de tener que «bosquejar el cuadro de una vida, cuyos hilos rotos flotan al acaso, de una vida que fue solo una mañana tempestuosa, aunque anunciaba ser un medio día espléndido y una serena y luminosa tarde». Su trayectoria había estado marcada por la desgracia con muchos «días sin pan, noches sin asilo y sin sueño, padecimientos físicos y congojas morales, en la eterna lucha del genio desamparado por salvar las frías barreras que de todos lados cercan y encadenan su vuelo.» (Campillo) En su necrología, Campillo embutió dos rimas: «Los invisibles átomos del aire» (rima X) y «Me ha herido recatándose en las sombras» (rima XLVI).

Isidoro Fernández Flórez dedicó buena parte de su sección de «Ecos» también a glosar su personalidad, pero centrando su atención en la poesía: «Los que han conocido a Gustavo Bécquer no podrán olvidar al amigo, pero los que han leído las poesías no pueden olvidar al poeta.» Y, para quienes no las conocieran, copió «Asomaba a sus labios una lágrima»-futura rima XXXy «Antes que tú me moriré, escondido»-rima XXXVII. Así se harían una idea los lectores «de su alma y de su genio». Un dibujo de Casado del Alisal, grabado por Rico y que representaba al poeta en su lecho de muerte, completa el sentido homenaje de la revista a su director. Antes se había publicado con el título «De un libro inédito» la rima IV: «No digáis que agotado su tesoro» (núm. 5, 12-III-1870).

Los dos artistas por lo tanto desaparecían prematuramente y rodeados de un halo de desdicha y de haberse malogrado por su temprana muerte. Su nutrida colaboración dispersa por las páginas de la revista resulta todavía hoy un argumento irrefutable de la importancia de ambos juntos: en el número 2: «Lápida monumental dedicada a la memoria de Miguel de Cervantes Saavedra» y «La picota de Ocaña». Número 3: «Labradoras del Valle de Amblés. Tipos de Ávila», «Una calle de Toledo», «Casa de los señores de Castril en Granada» (este con comentario de M. de Góngora). Número 4: «Enterramiento de Garcilaso de la Vega y de su padre en Toledo», «Pozo árabe de Toledo», «Aldeanos de Fuente Toba. Tipos de Soria», «Leñador de los pinares y pastor de Villaciervos. Tipos de Soria». Número 5: «Aldeanos del Valle de Loyola. Tipos vascongados». Número 12: «Octava del Corpus en Sevilla.-Los 
seises de la iglesia catedral». Número 12: «Las segadoras. Estudio de costumbres aragonesas.»

Naturalmente Gustavo Adolfo comentaba grabados basados también en otros dibujantes: de Casado del Alisal en el número 7, «La Semana santa. Una cofradía de penitentes en Palencia»; en el 12: «Las dos olas». De Vallejo: «Madrid Moderno. Techo pintado por el señor Vallejo con ornamentación de los Sres. Ferry y Busato en el nuevo Café de Fornos», etc.

También las imágenes de Valeriano a veces acompañaban a textos de otros colaboradores: «La Romería de San Isidro», poema de Emilio Álvarez, va ilustrado con dos espléndidos frisos de ciudadanos madrileños participantes en la fiesta: «La romería de san Isidro. Cómo van» y «La romería de san Isidro. Cómo vuelven» (núm. 9, 12-V-1870). Número 13: «Minarete de la gran mezquita de la Kutobía en la ciudad de Marruecos»-realizado a partir de una fotografía-, es complemento a «Marruecos» de Antonio de San Martín, que iniciaba una serie de artículos sobre aquel país. Continúa con nuevas entregas ilustradas por Valeriano en los números 14 a 16 sobre «Marruecos» describiendo las ciudades de Tánger y algunas costumbres, lo que da lugar a varios grabados de sobre dibujos del sevillano: «El aguador ambulante.- Tipo Marroquí», «Un arrabal de la ciudad de Marruecos», «Marruecos.- Hebrea en traje de fiesta». «Marruecos.- Mora en traje de fiesta.» Su fallecimiento cortó la colaboración.

Como Valeriano era dibujante oficial de la revista se ocupó también realizando dibujos preparatorios para grabados a partir de fotografías sobre el conflicto independentista cubano reavivado en aquellos años: "Voluntarios de La Habana» (núm. 10). Y sobre todo, cuando estalló la guerra francoprusiana, la revista trató de cubrir la información sobre el conflicto con detallados textos de Isidoro Fernández Flórez -desplazado al escenario de los acontecimientos- y con un gran despliegue gráfico para el que trabajaron sus grandes dibujantes: Perea, Pradilla, Manchón o Valeriano Bécquer. Del empeño que ponían en informar adecuadamente da cuenta su «Advertencia», incluida el 12 de agosto de 1870. Solamente un acontecimiento excepcional como aquel les hacía separar la vista de dar cuenta de la vida nacional como era su propósito habitual. Eran verdaderos reportajes gráficos que ayudaban a dar vida a los textos que analizaban la contienda y su valor informativo resulta nítido en sus largos títulos. De Valeriano Bécquer encuentro: «El rey Guillermo estableciendo el campamento de Kaiserslautern al avanzar el cuerpo del ejército de reserva prusiano». Y «Guerra ente Francia y Prusia. Batalla de Forbach. Los prusianos toman por asalto la meseta de Spickeren y obligan al general Frossard a la retirada.» (núm. 12, 12-VIII-1870). En el número 16: 
«La artillería francesa protege el paso del Mosela verificado por su vanguardia en Longueville.»

Desgraciadamente su trabajo se cortó repentinamente con su muerte a finales de septiembre y solamente pasados los meses reaparecerá su firma en grabados basados en dibujos adquiridos por la revista para ayudar a financiar la edición póstuma de las Obras de su hermano. Incluso la firma de Gustavo Adolfo desaparece prácticamente en los números de noviembre y diciembre de 1870 (una relación detallada en Rubio Jiménez, 2009). Estaba Gustavo Adolfo ya muy enfermo después de la grave bronquitis que padeció tras realizar el trayecto desde la Puerta del Sol hasta su domicilio en la calle Claudio Coello en la terraza descubierta de uno de los nuevos tranvías tirados por caballos, de los que por cierto acababa de proporcionar información revista: «Madrid moderno. Modelo de los coches del tranvía que ha de cruzar la población» (núm. 21, 12-XI-1870). Fueron los días más fríos vividos en Madrid en mucho tiempo (Lara, 1999). La línea completa del tranvía no se inauguraría hasta mediados de 1871, lo que dio lugar a otro espléndido grabado en $\mathrm{La}$ Ilustración de Madrid (núm. 35, 15-VI-1871). Era un elemento más que ponía la ciudad a la altura de las más avanzadas ciudades del Mundo en el transporte público.

El 27 de diciembre de 1870, abrió su último número del año La Ilustración de Madrid con una triste noticia:

Una nueva desgracia acaba de experimentar LA ILUSTRACIÓN DE MADRID. El Sr. D. Gustavo Adolfo Bécquer, su director literario, ha fallecido.

Tres meses hace que su hermano el inspirado dibujante, cuyas obras han admirados nuestros suscriptores, había muerto dejándole el alma traspasada de dolor. Una enfermedad de carácter crónico, pero cuyo imprevisto y extraordinario desarrollo ha sido debido a la soledad en que se encontró su alma, y a ese oculto fuego de la tristeza que consume rápidamente el cuerpo más joven y robusto, ha dado fin a sus días.

El profundo sentimiento que nos abruma es ajeno, hoy, como lo fue antes, en la época del ilustre pintor, a la consideración del gran vacío que dejan en estas columnas, uno y otro, lo mismo Bécquer artista, que Bécquer el poeta, genios no bastante conocidos y mal, muy mal recompensados por la suerte, eran dos ilustraciones patrias.

Era el anhelo de ambos que esta publicación se distinguiese de todas las demás de su índole, por su carácter exclusivamente español. LA ILUSTRACIÓN DE MADRID se encuentra sin dos de los más poderosos elementos con que contaba para realizar ese propósito; pero trazándose como invariable línea de conducta aquel levantado deseo, seguirá siempre consagrada al arte $\mathrm{y}$ a la literatura patrias.

¡Es el mejor y más digno tributo que podemos rendir a su memoria! 
En el próximo número publicaremos la biografía y retrato de D. Gustavo Adolfo Bécquer.

En el último apartado de su sección de «Ecos», Fernández Flórez daba cuenta ya de que se había abierto una suscripción para publicar las obras artísticas y literarias de los dos hermanos formando un álbum. Después el proyecto varió y solamente se publicaron en julio de 1871 las Obras del poeta ya que resultaba muy costoso editar grabados los dibujos de Valeriano (detalles en Rubio Jiménez, 2009).

La importancia y el interés de La Ilustración de Madrid y de sus dos Almanaques, sin embargo, van mucho más lejos de ofrecer abundantes textos y grabados becquerianos y precisamente porque en el planteamiento de la revista se daban pasos firmes hacia una considerable mejora artística de aquellas publicaciones ilustradas pintorescas y se hacía con una conciencia nítida de prestar un servicio a la educación del país. Rosario Álvarez Rubio ha sido quien ha realizado una mejor descripción de la revista atendiendo a estos intereses educadores, desglosando sus secciones para mostrar cómo la historia en un sentido amplio pero también otras disciplinas se hallan muy presentes en la revista, que buscaba así ser útil en la formación de los lectores. El propio subtítulo no deja lugar a dudas: «Revista de política, ciencias, artes y literatura». De los cuatro términos acaso el menos atendido fue el primero si por política se entiende atención a la actualidad política y a la opinión partidista. Hubo en este campo una voluntad de equilibrio e independencia empresarial, siguiendo los sucesos del día, pero sin estar sometida su línea editorial a ningún partido político concreto, si bien manteniendo la orientación liberal de sus mentores. Pasados bastantes meses de su andadura, el 15 de junio de 1871, sintieron la necesidad de incluir una «Advertencia» recordando que la revista la había fundado «una sociedad de aficionados al arte, que profesan las más encontradas opiniones políticas» y que «vio la luz pública haciendo la explícita declaración del firmísimo propósito que tenía de observar la más estricta neutralidad en la lucha de partidos, limitando sus aspiraciones en este punto a ofrecer en su columnas un palenque de ilustración y de ciencia.» Se equivocarían, insistían ahora, quienes quisieran desposeer a La Ilustración de ese carácter neutral.

Se hacía en cada número un balance de la quincena pasada y se abordaban los asuntos más sobresalientes, pero con voluntad sobre todo informativa. Ofrecieron, eso sí, semblanzas de políticos, acompañadas de sus retratos grabados. Tiene su lógica si se tiene en cuenta la intensa actividad política de aquellos años llenos de tanteos buscando crear y asentar un régimen político nuevo, incluido el pertinente proceso constituyente: Eugenio Montero Ríos 
(núm. 2), Francisco Serrano (núm. 2), Echegaray (núm. 4), Nicolás María Rivero (núm. 6), Ignacio Rojo Arias (núm. 12), Segismundo Moret Prendergast (núm. 13), Emilio Castelar (núm. 21), Francisco de Paula Montemar (núm. 22), Manuel Ruiz Zorrilla como presidente de las Cortes Constituyentes españolas (núms. 22 y 47), Luis María Pastor (núm. 23), Pascual Madoz (núm. 24), Antonio Ros de Olano (núm. 27), Cristino Martos (núm. 28), Práxedes Mateo Sagasta (núm. 33), Salustiano Olózaga (núm. 34), Antonio Cánovas del Castillo (núm. 35), Cándido Nocedal (núm. 37), Estanislao Figueras (núm. 37), Eduardo Gasset y Artime (núm. 38), Luis González Brabo (núm. 41), el Duque de la Victoria (núm. 42), Antonio de los Ríos y Rosas (núm. 43), Francisco Romero Robledo (núm. 46), etc. Actos como la apertura de las Cortes y la dinámica de la vida política parlamentaria marcaban la oportunidad de la publicación de estas semblanzas junto con avatares personales de los retratados como sus nombramientos o necrologías. ¿Cómo eludir por ejemplo informar literaria y gráfica la jura de la constitución por parte de Amadeo I? Le dedicaron cumplida información en el número 25.

Las funciones dentro de la revista estaban bien diferenciadas desde el comienzo: Eduardo Gasset y Artime era el Director General, Gustavo Adolfo Bécquer, el Director Literario, secundado por Isidoro Fernández Flórez como Redactor principal. El Director Artístico era José Vallejo Galeazo, secundado por Valeriano Bécquer como Dibujante y Bernardo Rico como Grabador. Un equipo directivo consistente y con altura de miras literarias y artísticas más allá de la necesaria viabilidad empresarial y con una intención de afirmación nacional indudable.

Al estar ligada al periódico El Imparcial, creado e impulsado por Eduardo Gasset y Artime, la revista contaba con el apoyo de su importante imprenta, que se mostró en sus páginas con un gran grabado de sus talleres en el número 10 (27-V-1870), resaltando en el comentario la modernidad y alta capacidad de su maquinaria, que permitía poner al alcance de sus lectores, en apenas doce horas, 348.000 ejemplares del periódico, que era su edición estimada en aquel momento.

No iba a tardar en surgir un primer objeto de litigio con la competencia porque mientras los impulsores de La Ilustración Española y Americana, que habían absorbido El Museo Universal, optaron por un planteamiento puramente capitalista de la empresa, comprando indiscriminadamente grabados en el extranjero, los promotores de La Ilustración de Madrid se impusieron restricciones y afirmaron su voluntad de contribuir a difundir el dibujo y el grabado realizados por artistas españoles, anunciando desde su comienzo explícitamente: «dibujos y grabados exclusivamente españoles». 
Ante la diferencia de trato que entendían daban los poderes públicos a quienes luchaban por favorecer y difundir el arte español y quienes no tenían más horizonte que el beneficio empresarial y por tanto importaban grabados sin tasa, el equipo de La Ilustración de Madrid no encontró mejor salida que renunciar a la subvención estatal que recibían por coherencia tal como dejaron constancia en el número 10 (27-V-1870) del conflicto surgido por las quejas de La Ilustración Española y Americana a que organismos públicos se suscribieran a La Ilustración de Madrid como forma de apoyo. Y el 27 de octubre de 1870, comunicando su renuncia a la ayuda estatal con un duro editorial donde se describe el pulso mantenido durante aquellos meses y las incongruencias de los responsables políticos, que no entendieron el alcance artístico de la empresa.

En todo el recorrido de la revista siguieron haciendo gala de este criterio de favorecer la creación artística nacional y todavía el 30 de julio de 1871, Isidoro Fernández Flórez, cuando trazó la encomiástica semblanza de su Director General, Eduardo Gasset y Artime, la concluía con estas palabras:

Él y sus compañeros, artistas y hombres de letras, quisieron únicamente dotar a España de una ILUSTRACIÓN exclusivamente nacional, donde el arte patrio pudiera manifestarse en su verdadero estado de perfección y progreso, sin acudir, como hasta ahora ha sido y es costumbre, a importar del extranjero las ilustraciones que han de servir para reproducir en estampa los acontecimientos políticos y sociales de nuestro propio país. Los que conocen la diferencia de precio que existe entre los grabados mandados hacer expresamente y los que se compran al peso, saben los grandes sacrificios pecuniarios que supone una publicación nacional de esta índole. El Director de El Imparcial y sus compañeros de LA ILUSTRACIÓN DE MADRID no se han detenido en su propósito por ningún obstáculo, y la iniciativa que Gasset ha tenido en este asunto será siempre un título de honor que le envidiarán los amantes de las letras y las artes patrias. (Fernández Flórez, 1871: 223)

Este mismo carácter vindicativo de la nación se hace patente en el espacio concedido a hacer visible el pasado glorioso de España que transversalmente ocupa espacio abundante en la revista y por ello, la inclusión de artículos de historia es habitual desde el primer número - «Memorias de don Gil Álvarez de Albornoz, cardenal y arzobispo de Toledo», por Antonio Cánovas; «La librería del cabildo de Toledo», por José M. Octavio de Toledo- y grabados destinados a hacer visible el patrimonio artístico de la nación y sus costumbres. En este aspecto, desde el impulso inicial de la revista resultó fundamental la labor de los hermanos Bécquer, Valeriano como dibujante y Gustavo Adolfo como comentarista: «Sepulcros de los Condes de Melito en Toledo», «Mayólica del siglo XVI del Museo Nacional de Escultura de Madrid», «El pordiosero. 
Tipo toledano». De Gustavo Adolfo Bécquer aún se añadía, además, «Antigüedades prehistóricas de España», que había sido escrito como prólogo a las Cartas prehistóricas de D. Manuel de Góngora, que se publicaron a partir del segundo número. Seguían las colaboraciones literarias donde también se adivina el peso modélico del pasado áureo español: «Un drama oculto de Lope», de Antonio Hurtado, cuadro de costumbres de los siglos XVI y XVII; «El capital y el trabajo, égloga contemporánea» de Luis de Eguilaz, novela cuyas entregas continúan en los números siguientes; una serie de 5 sonetos -«Desde la soledad»- de Antonio Ros de Olano; «Un recuerdo», de Carlos Rubio; el comienzo de la sección de «Teatros», firmada por Antonio Sánchez Pérez y hasta una crónica sobre «Troppmann», enviada desde París por Eusebio Blasco. Todo ello enriquecido con grabados de esmerada producción propia.

Los propósitos educativos de la revista, extendidos a todos los sectores sociales, son patentes también desde los primeros números: en el número 2, Francisco María Tubino reseña el notable ciclo de conferencias sobre la educación de la mujer dadas en la Universidad de Madrid. El 30 de marzo de 1871, en su número 30, incluían un discurso entero de Pi y Margall, apelando a la educación estética de las mujeres. Daban cuenta también sobre ciclos de conferencias populares (núm. 32) o fue habitual informar sobre todo tipo de actos culturales. El lugar social de la cultura y sus instituciones en general tendrá un lugar continuado en la revista, reseñando las actividades de las diferentes Academias. Se ocupaba de este menester el experimentado historiador medievalista Florencio Janer en la sección «Revista de los trabajos de las Academias y sociedades científicas, económicas y literarias».

La organización en secciones de la revista responde a esta voluntad pedagógica. Unas más concienzudas como la citada o la sostenida por José Amador de los Ríos, «Revista monumental y arqueológica» (núms. 10, 12, etc.), en otras ocasiones más vueltas hacia el presente para dar noticia de la vida social madrileña. La revista se abría cada quincena con la sección de actualidad, titulada «Ecos», con una crónica de sucesos notables firmada por Isidoro Fernández Flórez, salvo cuando no estaba presente en Madrid por haberse desplazado para cubrir con sus crónicas la guerra franco-prusiana; fueron los números 14 a 19, que firmó «J. Efebé». En el número 33, 15 de mayo de 1871, firmó los «Ecos» Roberto Robert, pero solo momentáneamente. Fernández Flórez como redactor principal de la revista mantuvo viva la sección durante los dos años que duró la publicación con su estilo ágil y con buena información del acontecer nacional y aun internacional.

Otras secciones daban cuenta también de la vida social; iban desde la crónica del gran mundo que ocupa el centro de los «Salones», de Ramos Chico 
de Guzmán (desde el núm. 2) a la sección de «Modas», que realizaba la poetisa Pilar Sinués de Marco, enriquecidas en ocasiones con grabados de eventos sociales o de figurines de moda.

Fieles a su programa divulgativo, la ciencia no faltó y José Jenaro Monti mantuvo viva la sección «Revista científica», que se completaba con la inclusión esporádica de artículos sobre asuntos científicos generales. Lo mismo se daba noticia razonada de un eclipse de sol como el ocurrido el 22 de diciembre de 1870 (núm. 24) -Rafael Montesinos vio en el suceso un signo extraordinario que acompañó la desaparición de Bécquer- como artículos sobre «Las manchas del sol» (núm. 5), de historia natural o acerca de otros países y su geografía y condiciones naturales. A veces con cierto toque exótico como en la información proporcionada sobre «Marruecos» en 1870, en la larga serie de siete artículos de Antonio de San Martín, que en parte ilustró Valeriano Bécquer. O China: «La embajada china en Madrid» con los embajadores chinos Chich-Kang y Sun-Chia-Ku enviados a España y retratados por Pradilla (núm. 15). La guerra franco-prusiana dio lugar, además, a colaboraciones con descripciones técnicas del armamento usado firmadas por Eduardo de Mariátegui.

Las distintas artes y la literatura ocuparon mucho más espacio en el conjunto de la publicación, combinando la existencia de secciones específicas con las colaboraciones que tuvieron también firmas especializadas. La historia de la nación ofrecía en sus distintas manifestaciones modelos a tener en cuenta y de aquí el goteo de artículos de carácter histórico: núm. 3, «El rey don Jaime y el obispo de Gerona», por Víctor Balaguer; E. Arjona y Laínez, «Felipe II y la liga católica de Francia» (núm. 13); José María Nogués, «Apuntes para la historia del príncipe Carlos» (núm. 21). Otras veces, se acudía a asuntos de índole local como Román Goicoerrotea con «Breves apuntes y noticias sueltas para escribir la historia de la ciudad de Tarazona» (núms. 23 y 24). Florencio Janer y José Amador de los Ríos complementaban sus secciones con colaboraciones sueltas obre asuntos de su especialidad: así el primero publicó una serie sobre «Trajes españoles en el siglo XV (núms. 16 y 17) o José Amador de los Ríos, «Ramón Lull (Raymundo Lulio), considerado como alquimista» (núm. 9), que tendría una tardía contestación en una carta editada en el número 44, discutiendo sus argumentaciones.

La creación artística al amparo de la tradición de la nación daba lugar a obras donde se entrecruzan diferentes tiempos: es muy nítida esta situación en la publicación de reproducciones de estatuas de escultores contemporáneos de grandes personajes del pasado para hacerlos visibles en monumentos públicos: «Lápida monumental» dedicada a Cervantes (núm. 2), cuyo 
grabado sobre dibujo de Valeriano Bécquer se reproduce acompañado por un comentario de Gustavo Adolfo (Rubio Jiménez, 2007); la estatua de «Santa Teresa de Jesús, ejecutada en mármol por don Elías Martín» (núm. 6), que da pie a comentarios sobre la significación histórica de la santa de Ávila; «Fray Luis de León» (núm. 10), esculpido por el señor Sevilla para coronar el monumento que le había dedicado la ciudad de Salamanca; el 15 de abril de 1871 incluyeron la «Estatua de Murillo, ejecutada por el señor Medina», para colocarla en el Paseo del Prado con lo que se le otorgaba públicamente toda su significación dentro de la escuela de pintura española; «El Cardenal Cisneros» era destacado en el número 36, combinando la descripción literaria y plástica de su suntuoso sepulcro y la reproducción de su efigie grabada, abriendo esta última la revista. Un permanente homenaje a Cervantes atraviesa toda $\mathrm{La}$ Ilustración de Madrid y se hace patente en artículos como el de «Patria de Cervantes. Pila en que fue bautizado en Alcalá de Henares», de Benigno García Archuelo (núm. 38, 30-VII-1871) o en las crónicas sobre cuestiones cervantinas de Francisco María Tubino: «Cervantina» (núm. 21), «El barrio de las musas» (núm. 26), «Aliaga, presunto autor de "Don Quijote el malo"» (núm. 31) y «Aliaga no es autor del falso Don Quijote» (núm. 39). También, Vicente Barrantes, «Proyecto ignorado de monumento a Cervantes (núm. 41); se hicieron eco también de los proyectos de crear un panteón de celebridades, que era otra forma de dar presencia pública a los genios de la nación y de rendirles tributo, un asunto que preocupó mucho en aquellos años de construcción de la nación liberal (Hernando Carrasco, 1987).

El peso y el valor modélico del pasado se muestran en la revista en otras manifestaciones como la ideación de cuadros de costumbres de los siglos XVI y XVII propuesta por Antonio Hurtado con el título de Galas de Madrid desde el número 2. Tuvo mucha mayor amplitud la serie de Julio Monreal, Costumbres del siglo XVII con estas entregas: «El día del Corpus y sus autos sacramentales» (núm. 12); «El corral de las comedias» (núms. 13, 14, 15), «Una pica en Flandes» (núms. 19, 20), «Una academia» (núms. 22, 23), «A estudiar a Salamanca» (núms. 25, 26, 27), «Un auto de fe» (núms. 33, 34), «Una belleza de entonces» (núm. 43) y «Una fiesta de toros» (núms. 47, 48).

Si un género tuvo desde el romanticismo gran importancia modélica para las costumbres de los españoles este fue el teatro, que en La Ilustración de Madrid comparece de diversas maneras. En primer lugar, en la sección de «Teatros», firmada por Antonio Sánchez Pérez, a quien sucedería en 1871 Peregrín García Cadena. Daban cuenta de los estrenos notables y entre estos ocupan siempre lugar relevante los de dramas áureos, que continuaban teniendo un valor modélico para las costumbres contemporáneas. La vida teatral seguía 
ocupando el centro de las diversiones públicas urbanas con lo que la sección de «Teatros» tenía especial relevancia. Reforzaron esta importancia del teatro clásico la inclusión de algunos trabajos eruditos que hacían más visible aquella tradición: Manuel Cañete realizó un cuidadoso acercamiento al «Teatro español del siglo XVI. El registro de representantes del valenciano Juan de Timoneda» (núms. 42, 43). Y Vicente Barrantes en «La serrana de la Vera» (núms. 26 al 32) ahondó en la tradición de este tema para pasar después a analizar y a reproducir los textos dramáticos de Lope de Vega y de Vélez de Guevara.

Otras veces, las incursiones en la literatura áurea eran más generales, como Manuel Juan Diana en «El Conde de Villamediana. Apuntes sobre su obra y escritos» (núms. 8, 9), curioseando en la leyenda personal del poeta. Una «Cédula de indulto del siglo $\mathrm{XV}$ » (núm. 7), fue glosada por el doctor Thebussem. O un simple episodio novelesco fue relatado por Gaspar Núñez de Arce en «Unos náufragos del siglo XVI» (núm. 11).

Ligada en buena parte a la vida teatral hay que considerar la sección de la «Revista musical», que firmó Emilio Arrieta y donde daba cuenta tanto de la actividad musical en los teatros como en otros ámbitos. Le sucedió en 1871 en esta ocupación otro documentado crítico musical, Antonio Peña y Goñi. Podía ampliarse para dar información sobre algún músico relevante en aquel momento como Ofenbach o Hilarión Eslava, cuya semblanza escribió J. M. Esperanza y Sola (núms. 26, 27). O se abría a discusiones sobre estética musical en la serie de «Cartas acerca de la cuestión de la ópera en España, dirigidas a Mr. Karl Pitters», por Antonio Peña y Goñi (núms. 35, 36, 37, 39).

Lo importante quizás sea señalar cómo esta literatura y todo este pasado artístico y literario español se cuelan por todos los intersticios de la revista formando una amalgama que une sus piezas y que hasta cuando se trate de teorizar sobre el nuevo teatro, se interpone como un filtro entre el pasado y la realidad presente. Se puede ejemplificar en propuestas como «Arte de hacer comedias» (núm. 8), de Fernando Martínez Pedrosa, que remeda los tratados clásicos sobre la comedia desde su título y aunque ofrece una reflexión sobre como debe ser la comedia de costumbres contemporáneas, la sombra de la comedia áurea y sus convenciones morales sobrevuelan la reflexión del solo aparentemente moderno tratadista.

Para estudio de la presencia del teatro en la revista tienen cierto interés, además, la inclusión de grabados con escenografías de dramas representados entonces; por un lado son una prueba evidente de que la empresa que estaba detrás de La Ilustración de Madrid permitía un esfuerzo en este sentido impensable en años anteriores cuando la información grafica sobre la vida teatral 
había sido muy escasa y poco fidedigna (se reutilizaban tacos grabados sin pudor alguno): la brillantez de los espectáculos era correspondida por la de su reseña gráfica en obras como Mignon, representada en el teatro del Circo (núm. 11) y que fue comentada por Bécquer. O las decoraciones del primer acto de Pizarro o la conquista del Perú (núm. 29) y la del primer acto de Los amores del diablo (núm. 32). A poco que se ahonda, aun un ejercicio aparentemente inocuo como el comentario de una decoración, se convierte en un ejercicio que trasciende a este carácter informativo primario. Baste un ejemplo: en el número 30 se reprodujeron a toda página las decoraciones de los actos segundo y tercero de la ópera Marina, seguidas de los retratos grabados de sus primeros intérpretes. Se trataba no solo de exaltar esta ópera sino que finalmente la ópera española podía presentar un fruto granado después de años de tanteos a la búsqueda de una ópera nacional digna de tal nombre.

$\mathrm{Y}$ al rebufo de estos planteamientos hay que considerar la creación de un canon de lo nuevo, siempre contrapesado por lo ya institucionalizado. Es llamativa en este sentido la constante atención que se presta a la vida de las Academias, un aspecto este que suele olvidarse cuando se analiza la cultura de la época que tenía gran relevancia desde que desde mediados de siglo en las academias se potenció una mayor presencia social de las mismas dentro de una operación de política cultural de hacer más visible la monarquía -como su inspiradora y benefactora de la cultura- y como recordatorio de que habían sido los monarcas Borbones sus impulsores desde su instauración en el siglo XVIII. Pero ahora se estaba en un tiempo nuevo: expulsada la reina Isabel II del país y en un periodo constituyente donde se barajaban distintos nombres para ocupar el trono y en algunos sectores abogando incluso por la instauración de la república. Sin embargo, el peso institucional adquirido por la cultura ya no era fácilmente prescindible y más teniendo en cuenta que el estado liberal veía en la creación artística una de sus bases de legitimación. Eran tiempos de cambios, pero en lo posible controlados. Existía conciencia de que se vivía un proceso de modernización, pero con la nostalgia de las inevitables pérdidas que suponía y se hacían patentes en la transformación del aspecto de la ciudad, surgiendo un «Madrid moderno»-así se titularán diferentes comentarios, casi una verdadera sección- en detrimento de otro más castizo que iba desapareciendo. La nostalgia del viejo Madrid se hace ya patente en «Madrid ha muerto» de José Fernández Bremón en el primer número de la revista. La literatura costumbrista en La Ilustración de Madrid está continuamente marcada por este contraste entre las costumbres del pasado y la ciudad moderna que pugna por desarrollarse. La presencia del pasado se manifiesta en las fiestas que acompañan el transcurrir del año que dan lugar a artículos 
sobre «La bendición de las palmas» (núm. 7), «La semana santa» (núm. 8), «La cruz de mayo» (núm. 9) con interesante despliegue de imágenes y un cuidado comentario de Bécquer; «La romería de san Isidro» (núm. 9), la «Romería de San Antonio de la Florida» (núm. 35)... En ocasiones escenas costumbristas madrileñas, ligadas a la estación del año: «Escenas de Madrid. La horchatería» (núm. 13), con dibujo de Perea y texto de Bécquer. Algunas tradiciones vinculadas a la historia de la ciudad también tuvieron cabida: de Joaquín Tomeo y Benedicto, «Tradiciones madrileñas. El cubo de la Almudena» (núm. 16) y «Tradiciones madrileñas. El caballero de Gracia» (núm. 19).

El viejo costumbrismo romántico aún alienta en escritos como «Costumbres populares. El apartado de los toros y la prueba de los caballos en la plaza de Madrid» (núm. 21) o en la descripción de un tipo característico de la fiesta por José Luis Alvareda [¿Albareda?], «El torero» (núm. 5), ilustrado por Casado del Alisal.

Pero había cambiado el horizonte y resulta mucho más atractiva la imagen de Madrid como ciudad moderna que desprenden muchas páginas de la revista donde se da cuenta de la transformación urbana constante que estaba viviendo la capital española. Más arriba me he referido al trazado de una línea de tranvías o era habitual informar sobre la construcción de modernos palacios y casas señoriales: «Palacio del duque de Uceda» (núm. 9): «Madrid moderno. Palacio del marqués de Portugalete» (núm. 10). «Techo de un salón del palacio del duque de Bailén y patio del mismo palacio» (núm. 37). Quizás, no obstante, en este aspecto las mejores páginas son las dedicadas a los nuevos espacios de la sociabilidad: «El casino y el café de La Iberia» (núm. 3), descritos por C. Navarro y Rodrigo. «Madrid moderno. Techo pintado por el Sr. Vallejo con ornamentación de los señores Ferri y Busato en el nuevo café de Fornos» (núm. 12), con un agudo comentario de Gustavo Adolfo Bécquer. «El Ateneo por dentro (Copia del natural)» (núm. 29), por Ahriman y por Roberto Robert en «El Ateneo por dentro» (núm. 34). La diversificación de la ciudad se mostraba también en sus locales y no falta información gráfica y literaria sobre una reunión de obreros en «Reunión en el café Internacional» (núm. 33). Esto por no insistir en la mucha información que proporcionan las secciones de «Ecos»y «Modas» y porque nos acercan más a la realidad de la vida de los artistas y de los ciudadanos menos afortunados. La inestabilidad en los empleos públicos seguía dejando muestras de literatura costumbrista en el tratamiento de «Los cesantes» (núm. 31) en el artículo de E. Zamora Caballero. Y las miserables condiciones de vida de los literatos quedan patentes en la reimpresión de un viejo trabajo de Pedro Antonio de Alarcón, «La 
nochebuena del poeta» que seguía vigente (núm. 48) y daba lugar a constantes variaciones cuando se acercaban las fechas navideñas.

Para atender la curiosidad de los lectores, la revista seguía incluyendo modalidades literarias establecidas durante los decenios anteriores como la literatura de viajes de la que se ofrecen dos contribuciones del prolífico Emilio Castelar, «Recuerdos de una Semana santa en Roma» (núm. 3) y «Memorias del destierro. Capítulo primero de un libro inédito» (núm. 35). Algunas ciudades no españolas más iban a tener cierta presencia en la revista: Carlos Rubio, «Un recuerdo» (núm. 1), enriquecido con la narración de una tradición lisboeta. Pero esta literatura se orientaba ya en gran parte hacia la descripción del turismo veraniego: «Excursiones veraniegas», por Antonio Sánchez Pérez (núm. 38). O fiestas de ciudades españolas que adquirían una especial relevancia como las «Fiestas del Pilar en Zaragoza. El Rosario» (núm. 44) y «La feria de Gerona» (núm. 46).

Abundan la literatura y las imágenes destinadas a hacer visible el patrimonio artístico del país, aspecto este en el que jugaron un papel decisivo las directrices de Gustavo Adolfo y las publicaciones realizadas con su hermano a las que ya he aludido. Se puede completar con otras referencias: Joaquín Tomeo y Benedicto, «San Juan de la Peña (Recuerdos)» (núm. 9); Ricardo Villanueva, «El castillo y tierra de Coca, antigua Cauca (Segovia)» (núm. 27); Vicente Barrantes, «Monasterio de Yuste» (núm. 35); «El pórtico de la Gloria de la catedral de Santiago y el museo de South Kensington de Londres» (núm. 38), por Fernando Fulgosio; o «Recuerdos arqueológicos y monumentales de Palencia», de José Amador de los Ríos (núms. 44, 45). Ligadas a lugares o a monumentos, determinadas tradiciones seguían gozando de gran aceptación por parte de los lectores. Luciano García del Real, ofreció algunas Tradiciones asturianas: «Mari-cuchilla» (núm. 8), «La peña del castigo» (núm. 13) y «El ermitaño» (núm. 27). Juan de Dios de la Rada y Delgado, «Tradiciones gallegas. La compaña» (núm. 14).

El contraste lo ofrecía la atención prestada a nuevas construcciones donde alentaba la renovación del país como pudo ser la «Inauguración del colegio de San Juan Bautista en Santoña» (núm. 38); otro tanto cabe decir de la información sobre la Exposición de Bellas Artes en 1872 (núms. 43, 44, 45, 46, 47), sobre la Exposición de Barcelona (núm. 45) o incluso un establecimiento hotelero en la playa de Bilbao que era visto como signo inequívoco de la modernización del país y que describe G., en una carta fechada en Las Arenas, 16 de agosto de 1871 y dirigida «Señor Director de La Ilustración de Madrid», dando lugar a una hermosa crónica -también gráfica- de los equipamientos costeros para el veraneo. 
Como corresponde a una revista alentada por literatos y artistas atentos a las corrientes más actuales de la literatura, sus páginas ofrecen un muestrario de los distintos géneros y también sus grabados fueron componiendo una galería de nombres significativos del panorama de entonces. Algunos llegaron a colaborar en la revista pero otros representan o bien las generaciones anteriores o bien alguna circunstancia los llevaba a las páginas de la revista. No tuvieron en este sentido, una especial atención en promocionarse. Un repaso ofrece -dejando a un lado a quienes ya han sido nombrados como políticos aunque compaginaran esta labor con la escritura- esta relación: cuando se refieren a escritores de la generación romántica, básicamente son homenajes o necrologías. De Antonio García Gutiérrez, además de glosar su personalidad (núm. 31), incluyeron algunos poemas: «La tumba ignorada» (núm. 5), «Poesía» (núm. 6). Manuel Bretón de los Herreros recibió en cierto modo un homenaje de la revista, porque además de su retrato grabado se ofreció un sentido poema sobre Quel, su lugar de nacimiento: «Mi lugar», enriquecido con una vista pintoresca de la población riojana (núm. 21). Esta idea de homenaje se refuerza con la inclusión del poema de Hartzenbusch, «Al Excmo. D. Manuel Bretón de los Herreros. Romance» (núm. 21); y también publicaron después de Hartzenbusch, «El estañero aburrido. Fábula» (núm. 47). La necrología del erudito escritor Juan Rico y Amat dio lugar a la publicación de su retrato (núm. 23); gentes del mundo del teatro o cercanos tienen un lugar relevante: Cristóbal Oudrid (núm. 28), José Valero (núm. 32), Matilde Díez (núm. 33) Severo Catalina (núm. 44), Joaquín Gaztambide (núm. 5), Adelardo López de Ayala (núm. 7). Músicos: Emilio Arrieta (núm. 23), Hilarión Eslava (núm. 26), Jesús Monasterio (núm. 29). Escritores contemporáneos como Juan Valera y Alcalá Galiano (núm. 9) y Luis Eguilaz (núm. 28). Motivaciones más informativas que de autopromoción parecen haber regido esta selección, que se completa con algunos artículos acerca de la situación de la literatura, que oscilan entre las quejas sobre su supuesta decadencia entonadas por Pablo Nougués, «Estado de la literatura en España y principales causas de su decadencia» (núm. 36), que acumula una sarta de lamentaciones, a algún intento de definir el horizonte inmediato del que procedía el periodismo que cultivaban como el ponderado artículo de Luis Carreras sobre «Espronceda y Larra» (núm. 17). No se puede decir por lo tanto que se defendiera una sola línea literaria sino que la revista fue ecléctica en la publicación de textos de creación literaria por lo que se pueden muestrear diferentes autores y modalidades poéticas. Sin ánimo exhaustivo: si pensamos en la poesía iniciada por poetas cercanos a Gustavo Adolfo, además de las rimas de Bécquer incluidas -y ya citadas- se pueden espigar poemas de otros poetas de su círculo o una sentida 
reseña en su sección de «Ecos» de Isidoro Fernández Flórez, de La pereza (1871) de Augusto Ferrán donde destacaba el «Prólogo» de Bécquer -como es sabido, en realidad era la reseña de la primera edición de este poemario con el título de La soledad (1860)-, entresacaba tres cantares destacando el valor de la pereza creativa y copiaba también la composición XXXIV: «El dulce sonido...» (núm. 46).

Durante aquel decenio, la poesía de cantares que había promovido Augusto Ferrán se había convertido en un género muy cultivado y como muestra pueden verse las colaboraciones de José de Fuentes, «Cantares» (núms. 5, 24, 25, 46). Poeta del círculo de amigos de Gustavo Adolfo, pero de escasa producción todavía dispersa por periódicos y revistas fue Ramón Rodríguez Correa de quien se incluyen «Mis días» (núm. 37) y «El organillo» (núm. 37). Del versátil Manuel del Palacio dos colaboraciones que se sitúan en el territorio fronterizo de la traducción-imitación: «El Valle de la muerte (Traducido del alemán)» (núm. 4), «Armonías íntimas (Imitación de Zanella) (núm. 14). Narciso Campillo, «A unos ojos» (núm. 13), mantiene sus convencionalismos clasicistas habituales, mientras en Pedro María Barrera se detecta una mayor modernidad y acercamiento a la poesía de Lamartine: «Melodías» (núm. 20), «Como el oro más puro» (núm. 24). El despeñadero sentimental se aprecia en Faustina Sáez de Melgar, «Melancolía» (núm. 31) y E. Sánchez de Fuentes, «A una golondrina».

Ramón de Campoamor representaba otra de las tendencias en auge con sus poemas entre narrativos y reflexivos: «El busto de nieve» (núm. 3); de «El tren expreso. Poema en tres cantos» (núms. 33, 34), incluyeron el canto primero; «Los grandes problemas» (núm. 45), anticipo de su libro Pequeños poemas. Por este camino se caía con facilidad en el filosofismo de bajo vuelo: M. Ortiz de Pinedo, «Pensamientos sueltos» (núm. 34). Francisco Flores García, «La vida» (núm. 44).

Poesías de un incipiente descriptivismo realista: J. Federico Muntadas, «La gruta» (núm. 19), relativa al descubrimiento de cascada de La cueva de la cola de caballo en el monasterio de Piedra que dio lugar a abundante literatura entre pintoresca y sublime, encabezada por él mismo. Antonio de Trueba, «Ancreóntica realista» (núm. 42). En muchos casos seguía vigente la poesía patriótica de antaño: Antonio Ros de Olano, «La viuda del patriota y su hijo. 1808» (núm. 6). Poesías llenas de tópicos del primer romanticismo: Francisco Luis Retes, «Rodrigo» (números 7, 8). Luis Vidart, «El fantasma» (núm. 28).

Muchos de aquellos poemas eran meramente de circunstancias o simples ejercicios más o menos discretos con temas y formas que respondían a diferentes usos sociales de la poesía: Desde el ejercicio académico de Manuel 
de la Revilla, «¡Paso al invierno!» (núm. 31) traducción de Víctor Hugo, a «Metamorfosis» (núm. 34). De Ventura Ruiz Aguilera, «Ruego» (núm. 4). De Joaquín Tomeo y Benedicto, «Cántiga. A Olvido» (núm. 14). Adelardo López de Ayala, «Sonetos: «La cita» y «Sin palabras» (núm. 24). Antonio Cánovas, «Despedida» (núm. 37). Antonio Hurtado, «Recuerdo tradicional de la Virgen de la novena» (núm. 10). Ernesto García de Ladevese, «Canto de los marineros» (núm. 31). Peregrín García Cadena, «La Noche-buena del cesante» (núm. 48). Gabriel García Tassara, «A la insigne poetisa doña Carolina Coronado de Perry» (núm. 46),...

Más difíciles de categorizar son colaboraciones como los dieciocho «Pensamientos» de Manuel Murguía publicados el 27 de octubre de 1870 (núm. 20), pequeños poemas prosa con un repaso amplio de temas y de textura que anuncia el camino que conducirá a la prosa modernista. Esta misma voluntad de acercamiento a la expresión lírica trascendiendo lo meramente descriptivo se aprecia en Fernando Redondo, «La noche en el bosque (Fragmentos de unas memorias inéditas)» (núm. 23).

Fueron tiempos también de transición de gustos y formas en la narrativa. En varios casos, no es fácil diferenciarlos de la literatura costumbrista con sus características escenas: Roberto Robert, «La que espera en el café» (núm. 23); Peregrín García Cadena, «Historia breve y compendiosa de una persona decente» (núm. 40), «El melocacto. Historia para las niñas casaderas» (núm. 32); Salvador María Granés, «Viaje al corazón de una mujer» (núm. 27); Antonio Hurtado, «Historia de un desconocido» (núms. 40, 41, 44); Fernando Martín Redondo, «Placeres inocentes» (núm. 36); José Fernández Bremón, «El dios de las batallas» (núm. 26), «El vil metal» (núm. 28); Florencio Moreno Godino, «Un golpe de estado (núm. 10).

En otros casos marcadas por la presión de las fechas: Ahriman, «iPavos! ¡Pavos! Fantasía de Noche-buena» (núm. 48); las colaboraciones de Asmodeo, «Cartas fashionables» (núms. 33, 34) se hallan también entre la escena de costumbres, el cotilleo social y el relato breve. Pasos hacia el moderno cuento literario con su variedad de formas suponen relatos como: Salvador María Granés, «Episodios de la vida de un caballo, contados por él mismo» (núm. 24); Álvaro Romea, «No hay deuda que no se pague... Cuento original» (núms. 32, 33, 37, 40, 44, 48) y José Fernández Bremón, «El tonel de cerveza. Cuento» (núms. 36, 37).

Que viejos modelos como el diálogo lucianesco seguían gozando de cierta vigencia lo demuestra Ahriman con «Los quijotes y los sanchos. Dialogo de ultratumba» (núms. 41, 42) donde desfilan y dialogan diferentes personajes 
clásicos españoles. Pero también cierta sugestión arqueologista en Santiago de Liniers, «El rey Caudaulé, cuento greco-latino» (núms. 20, 21, 22, 23, 24).

El afán por analizar y dejar constancia narrativamente de los problemas de la sociedad española contemporánea, que estará en la base de la formulación del programa novelesco de Clarín o Galdós, queda manifiesto igualmente en algunos de los relatos más extensos incluidos a veces durante varias entregas en la revista: Luis de Eguilaz, El capital y el trabajo. Égloga contemporánea (núms. 1, 2, 3, 4). Moneda corriente. Viaje a través de algunas preocupaciones españolas (núms. 10, 11). En otros casos se modulaba con la apertura a registros fantásticos: José Fernández Bremón, En el cuerpo de un amigo, novela diabólica (15 entregas entre los números 5 y 19). Antonio de San Martín, El barco fantasma (novela original) (núms. 28, 29). Y el relato que más se ha citado de cuantos incluyó la revista por la nombradía de su autor fue el de Benito Pérez Galdós La novela en el tramvía [sic] (núms. 46, 47). Ha sido objeto de numerosos análisis por su carácter germinal y su sorprendente complejidad, contraponiendo la realidad y al fantasía, lo vivido y lo soñado, la literatura leída y las ensoñaciones que suscita (comparecerán ahí los vuelos aéreos y aun el mundo submarino), el ambicioso montaje de sus secuencias (Gullón, 1983. Sánchez Fernández y Padilla Mangas, 1990. Smith, 1992,...). Y todo ello siguiendo el trayecto del recorrido del nuevo tranvía que llevaba desde el barrio de Salamanca hasta el de Pozas, con sus diferentes paradas y cambios de paisaje urbano. Quizás no se ha prestado toda la atención a la hábil explotación por parte de Galdós de una novedad madrileña como eran los tranvías, según se ha visto. Caminaba indudablemente con paso firme a convertirse en el novelista por excelencia de esta ciudad moderna, que iba delimitando sus perfiles. No es posible analizar aquí este sugestivo relato que ilustra por sí solo la riqueza narrativa que se respiraba en aquel ambiente mientras se estaba cambiando no solo de régimen político, sino de decenio y desde luego de formas narrativas. Es todo un síntoma de este nuevo horizonte la variedad de lecturas que se agolpan en la mente de este soñoliento viajero que se deja llevar por la fantasía mientras va atravesando la ciudad de Madrid. No se ha escrito todavía el necesario libro que analice morosamente la enorme variedad de tanteos narrativos que se dieron en los años sesenta y que anunciaban en muchos casos la gran explosión de la novela y el cuento realistas de las décadas siguientes. En revistas como La Ilustración de Madrid se hallan sugestivos relatos que ayudarán a perfilar esos horizontes de transición hacia el realismo. Incluso alguna reflexión de carácter teórico reclamando el alejamiento de los relatos fantasiosos destinados a fundamentar mitologías locales que sustentan 
sus incipientes nacionalismos: Antonio de Trueba, «Las novelas genealógicas» (núm. 43).

Si el lector ha seguido hasta aquí el curso de esta sucinta descripción de La Ilustración de Madrid orientada a descubrir y mostrar sus muchas vetas de nobles metales literarios y artísticos creo que encontrará justificada la consideración inicial de que se trata de una publicación fronteriza entre la continuidad de ciertos géneros románticos y una presencia notable de nuevas propuestas que apuntan hacia lo que iba a ser más característico en los años setenta en la narrativa o en la poesía. Y no menos importante y hasta singular resulta su empeño en difundir las obras plásticas de artistas españoles. Todo ello fruto de un sostenido empeño orientado a fomentar la educación de los lectores como una parte más de la construcción de la moderna conciencia nacional a la que aspiraban los mentores de aquella publicación quincenal.

\section{Bibliografía citada}

Almanaque de la Ilustración de Madrid para 1871, escrito e ilustrado por los principales colaboradores de este periódico, Madrid, Imprenta y Estereotipia de El Imparcial, 1870.

Almanaque de la Ilustración de Madrid para 1872, escrito e ilustrado por los principales colaboradores de este periódico, Madrid, Imprenta y Estereotipia de El Imparcial, 1871.

Álvarez Rubio, María del Rosario, «La Ilustración de Madrid (1870-1872) Un regard sur l'Espagne culturelle et sur ses provinces dans la seconde moitié du XIXe siècle», Presse, Nations et Mondalisation au XIXe siècle, ed. Marie-Ève Thérenty y Alain Vaillant, separata, s. d., pp. 191-206.

BALBín LUCAS, Rafael de, «Sobre una colaboración desconocida de Bécquer y Rodríguez Correa«, Revista de Literatura, VI, 11-12, julio-diciembre de 1954, pp. 211-220.

Cabra Loredo, María Dolores (ed.), La Ilustración de Madrid. Textos de Gustavo Adolfo Bécquer acompañados de dibujos de Valeriano Bécquer, publicados durante los años de 1870 y 1871 en La Ilustración de Madrid, Madrid, El Museo Universal, 1983.

CAmpILlo, Narciso, «Gustavo Adolfo Bécquer», La Ilustración de Madrid, 25, 15I-1871, pp. 2-3.

FERNÁNDEZ FlÓREZ, Isidoro, «Ecos», La Ilustración de Madrid, 25, 15-I-1871, pp. $1-2$.

—, «Excmo. Señor don Eduardo Gasset Artime», La Ilustración de Madrid, 38, 30-VII-1871, pp. 222-223.

GulLón, Germán, La novela como acto imaginativo, Madrid, Taurus, 1983. 
Hernando Carrasco, Javier, Las Bellas Artes y la revolución de 1868, Oviedo, Universidad de Oviedo, Servicio de Publicaciones, 1987.

LARA, Juan Carlos de, «El frío que mató a Bécquer», El gnomo, boletín de estudios becquerianos, 8, 1999, pp. 11-26.

La Ilustración de Madrid. Revista de política, ciencias, artes y literatura. Dibujos y grabados exclusivamente españoles. Colaboración de los más distinguidos literatos y artistas, Madrid, Imprenta de El Imparcial y la Ilustración de Madrid, Plaza de Matute, número 5, 1870-1872, 2 tomos. In folio.

PAGEARD, Robert, «La mort de Gustavo Adolfo Bécquer dans la presse du temps (1870-1871), Bulletin Hispanique, LIX, 1957, pp. 396-403.

- Bécquer. Leyenda y realidad, Madrid, Espasa Calpe, 1990.

R. C. R. [Rodríguez CorreA, Ramón], «Don Valeriano Domínguez Bécquer», La Ilustración de Madrid, 19, 19-X-1870, pp. 15-16.

Rubio JimÉneZ, Jesús, La fama póstuma de Gustavo Adolfo y Valeriano Bécquer, Zaragoza, Prensas Universitarias de Zaragoza, 2009.

- «Los hermanos Bécquer y Cervantes. Una aproximación», Ínsula, 727-728, 2007, pp. 24-26.

SÁINZ DE Medrano, Luis, «Bécquer en La Ilustración de Madrid», Revista de Estudios Hispánicos (Universidad de Alabama), IV-2, 1970, pp. 291-302.

SÁNCHEZ FERNÁNDEZ, Ascensión y Padilla Mangas, Ana, «Acercamiento a la narrativa corta de Benito Pérez Galdós: La novela en el tranvía», IV congreso internacional galdosiano, Las Palmas de Gan Canaria, 1990, vol. II, pp. 823-833.

SMith, Alan E., Los cuentos inverosímiles de Galdós en el contexto de su obra, Barcelona, Anthropos, 1992.

Fecha de recepción: 06/04/2014

Fecha de aceptación: 30/11/2014

Anales, 26, 2014, pp. 451-471 